\title{
FOLFIRI regimen: an effective second-line chemotherapy after failure of etoposide-platinum combination in patients with neuroendocrine carcinomas grade 3
}

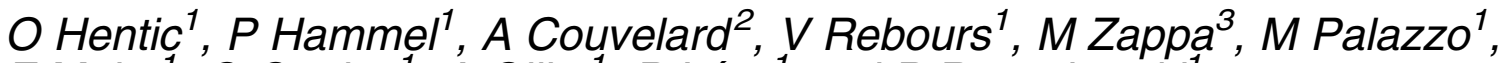 \\ F Maire $^{1}$, G Goujon $^{1}$, A Gillet $^{1}, P$ Lévy $^{1}$ and $P$ Ruszniewski ${ }^{1}$
}

${ }^{1}$ Pôle des Maladies de L'appareil Digestif, Service de Gastroentérologie-Pancréatologie, ${ }^{2}$ Service de Pathologie, and

${ }^{3}$ Service de Radiologie, Hôpital Beaujon, 100 Boulevard du Général Leclerc, 92110 Clichy, France

(Correspondence should be addressed to O Hentic; Email: olivia.hentic@bjn.aphp.fr)

\begin{abstract}
Patients with neuroendocrine carcinomas (NECs) grade 3 have a poor prognosis. Etoposideplatinum combination is the standard chemotherapy but the role of a second-line therapy remains unknown. Irinotecan alone or in combination has shown some efficacy in patients treated for small cell lung cancer which had pathological similarities with neuroendocine tumors. The aim of this study is to determine safety and efficacy of the FOLFIRI regimen in patients with NECs grade 3 after failure of etoposide-platinum combination. This study was retrospective, including patients with NECs grade 3 and treated with the FOLFIRI regimen after progression or toxicity of etoposide-platinum combination in first-line. Patients with Eastern Cooperative Oncology Group (ECOG) performance status $\geq 3$ and/or serum alkaline phosphatase $\geq 5 \times$ upper limit of normal value (ULN) and/or bilirubin $\geq 1.5 \times$ ULN were excluded. Among 39 patients who failed etoposideplatinum combination, 19 (49\%; 12 women, median age 53 (29-78) years) received the FOLFIRI regimen with a median number of $6(1-16)$ courses. Six patients $(31 \%)$ had at least one episode of grades 3-4 toxicity (neutropenia, $n=3$; diarrhea, $n=3$ ) without toxic death. Six patients $(31 \%)$ had objective response, 6 (31\%) stable disease, and 7 (38\%) tumor progression. Median progressionfree survival under FOLFIRI was 4 months. Overall survival was 18 vs 6.8 months in noneligible patients. FOLFIRI regimen is a safe and potentially efficient chemotherapy given as second-line in patients with NECs grade 3 who remain in good condition and with correct liver tests after failure of etoposide-platinum combination. These results should be confirmed in a future prospective study.

Endocrine-Related Cancer (2012) 19 751-757
\end{abstract}

\section{Introduction}

Malignant digestive neuroendocrine tumors (NETs) are rare with heterogeneous natural history (Yao et al. 2008). Major prognostic factors are tumor differentiation, Ki-67 index, and presence of liver metastases (Madeira et al. 1998, Panzuto et al. 2005, Hentic et al. 2011). Most digestive NETs are well differentiated; and even when the disease is metastatic, prognosis remains good with a 5-year overall survival of 60-90\% (Madeira et al. 1998, Panzuto et al. 2005, Hentic et al. 2011). Several treatment modalities are available, than can be adapted to the type of primary, functional status, tumor evolutivity, and tumor spread. Whenever possible, surgery has to be considered first and when it is not feasible, chemotherapy is proposed to patients with progressive disease or with large liver burden ( $\geq 50 \%$; Steinmuller et al. 2008). In case of malignant well-differentiated NETs, tumor growth is slow and tumor response rate with chemotherapy is usually low. Poorly differentiated endocrine carcinomas (PDECs) are very rare as they represent only 5-10\% of digestive NETs (Nilsson et al. 2006, Ahlman et al. 
2008, Bettini et al. 2008). At the time of diagnosis, patients are generally in poor condition due to aggressive and diffuse disease. These tumors are characterized by aggressive histological features (high Ki-67 index, extensive necrosis, and nuclear atypia) and are classified as neuroendocrine carcinomas (NECs) grade 3 according to the new World Health Organization (WHO) 2010 classification (Rindi et al. 2010). Etoposide-platinum combination is the gold standard for NECs grade 3, with a major antitumoral activity and high tumor response rates (41-67\%) reported in the main series published in the 1990s (Moertel et al. 1991, Mitry et al. 1999, Fjallskog et al. 2001). However, prognosis is poor with median progression-free survival of 9 months and median overall survival of 15-19 months. In this rare type of tumor, the potential role of second-line chemotherapy is unknown (Moertel et al. 1991, Mitry et al. 1999, Fjallskog et al. 2001). Combination of 5-fluorouracil (5-FU), leucovorin, and irinotecan (FOLFIRI) appeared to be of limited efficacy in malignant welldifferentiated pancreatic NETs (Ducreux et al. 2006, Brixi-Benmansour et al. 2011) but irinotecan-based regimens have demonstrated promising antitumoral activity in small cell lung cancer, which share similar pathological features (Langer 2001b, Noda et al. 2002). The aim of our retrospective study was to assess the feasibility, tolerance, and efficacy of FOLFIRI regimen as second-line treatment after failure of etoposide-platinum combination in a large monocentric series of patients with NECs grade 3 .

\section{Patients and methods}

\section{Selection of patients}

All consecutive patients with NECs grade 3 were included in this retrospective study in the Pancreatology and Gastroenterology Department of Beaujon University Hospital between 09/2000 and 10/2010. Median follow-up from the diagnosis was 29 (1.6-30.5) months.

The diagnosis of NECs grade 3 was performed by a single pathologist with experience in digestive NET by both histology and immunohistochemistry techniques (neuron-specific enolase, chromogranin A, and Ki-67 expression were at least required for each case) and classified according to the WHO 2010 classification (Rindi et al. 2010).

All patients with equivocal pathological diagnosis, that is, mixed tumors (MANEC according to the WHO 2010 classification), histologically well-differentiated neoplasms with Ki-67 $>20 \%$, or poorly differentiated nonendocrine carcinomas with no expression of neuroendocrine markers were excluded (Rindi et al. 2010).

The primary tumor and distant metastases were localized in all patients using abdominal and thoracic computed tomography (CT) scan and somatostatin receptor scintigraphy (SRS) and/or positron emission tomography with 18 fluorodeoxyglucose. Endoscopic ultrasonography of the duodenopancreatic area, upper and lower gastrointestinal endoscopy examinations were performed when necessary.

Treatment was decided during a weekly multidisciplinary board dedicated to NETs. In patients with unresectable NEC grade 3, a first-line chemotherapy consisted of a combination of etoposide-platinum salt (etoposide $100 \mathrm{mg} / \mathrm{m}^{2}$ on days 1,2 , and 3 plus cisplatin $45 \mathrm{mg} / \mathrm{m}^{2}$ on days 2 and 3 every 28 days or carboplatin area under curve (AUC) 5 on day 1 every 21 days). After progression or toxicity (mainly neurotoxicity $>$ grade 2) requiring treatment discontinuation, FOLFIRI regimen was proposed as second-line therapy as a systematic policy apart from 09/2000.

Criteria for treatment initiation are as follows: ECOG performance status 0-2, alkaline phosphatase $<5 \times$ the upper limit of normal value (ULN), bilirubin $<1.5 \times \mathrm{ULN}$, creatinin clearance $>60 \mathrm{ml} / \mathrm{min}$, neutrophil count $>1500 / \mathrm{ml}$, platelet count $>100000 / \mathrm{ml}$, and albumin $>28 \mathrm{~g} / \mathrm{l}$. When one of these criteria was not fulfilled, best supportive care (BSC) was decided.

\section{Treatment}

FOLFIRI combination consisted of irinotecan $180 \mathrm{mg} / \mathrm{m}^{2}$ on day 1 , followed by $400 \mathrm{mg} / \mathrm{m}^{2}$ folinic acid in a 2-h infusion, a $10-\mathrm{min}$ bolus of $400 \mathrm{mg} / \mathrm{m}^{2}$ 5-FU, and $1200 \mathrm{mg} / \mathrm{m}^{2}$ 5-FU in a 44-h infusion (days 1 and 2) every 14 days. Antiemetic prophylaxis using metoclopramide, ondansetron, and methylprednisolone was systematically proposed and was reinforced when necessary.

Patients who received at least one cycle of FOLFIRI were considered eligible for the study. Chemotherapy was stopped in case of unacceptable/life-threatening adverse event, performance status deterioration (i.e. ECOG $\geq 3$ ), hepatic laboratory tests worsening, and/or tumor progression on imaging.

\section{Safety and efficacy}

Baseline assessment included medical history, physical examination with evaluation of ECOG performance status, and biological tests (blood cell count, serum creatinin and creatinin clearance according to CockroftGault formula, bilirubin, alkaline phosphatase). During the treatment period, blood tests, evaluation of toxicity, 
and physical examination were performed before each cycle.

Toxicity was graded according to the National Cancer Institute Common Toxicity Criteria (NCI-CTC) version 2 . Chemotherapy was delayed in case of $\geq$ grade 2 toxicity; doses of irinotecan and 5-FU (short and long infusion) were reduced by $20 \%$ in case of $\geq$ grade 3 diarrhea or $\geq$ grade 3 neutropenia/thrombopenia.

Tumor response rate was assessed by CT scan at 3-month intervals according to Response Evaluation in Solid Tumors (RECIST) criteria (Therasse et al. 2000). The best response was considered among all response assessments. Evaluation procedures were performed ahead of schedule if patient's general condition deteriorated or severe toxicity occurred.

Overall survival was calculated from the day of diagnosis of NEC grade 3 to the day of death. For patients receiving FOLFIRI regimen, progression-free survival was calculated from the day 1 of first chemotherapy cycle until clinical and/or morphological progression. This study was approved by the Institutional Review Board of Beaujon Hospital.

\section{Statistical analysis}

Quantitative data were expressed as medians (range). Survival rates were calculated according to the Kaplan-Meier method.

\section{Results}

\section{General patient characteristics}

After a median number of six courses (1-16), etoposide-platinum combination was discontinued in 39 patients due to tumor progression $(n=34)$ or severe neurotoxicity $(n=5)$. Among them, 19 (49\%) were eligible for FOLFIRI regimen; in 14 patients, this switch was decided due to a progressive disease and in the remaining five patients, due to a toxicity of the platinum regimen. Fifteen patients were not eligible due to their poor general condition (ECOG $\geq 3$ ) and five patients, due to severe cholestasis. There were 12 women and seven men with a median age of 53 (29-78) years and with a performance status of 0-1 $(n=14)$ or $2(n=5)$. The site of primary tumor was pancreas $(n=10)$, liver $(n=6)$, anorectal $(n=2)$, or pelvic $(n=1)$. All patients had metastatic disease except one who had a locally advanced pancreatic carcinoma. The median Ki-67 index was 50\% (21-100\%). Median number of FOLFIRI courses was 6 (1-16). Treatment was started with reduced dose $(-20 \%$ irinotecan $)$ in $5(26 \%)$ patients due to abnormal liver tests $(n=3)$ or poor general condition $(n=2)$. FOLFIRI was stopped in 16 patients $(84 \%)$ due to clinical or radiological progression and in one due to grades 3-4 hematological toxicity. Treatment was still going on in two patients at the time of analysis (Table 1).

Table 1 Clinicopathological and somatostatin receptor scintigraphy features in the 19 patients with neuroendocrine carcinoma grade 3 treated with FOLFIRI regimen

\begin{tabular}{|c|c|c|c|c|c|c|c|c|c|}
\hline Patients & Age & Sex & $\begin{array}{c}\text { ECOG } \\
\text { performance } \\
\text { status }\end{array}$ & $\begin{array}{l}\text { Primary } \\
\text { site }\end{array}$ & Ki-67 (\%) & $\begin{array}{l}\text { Type of } \\
\text { cells }\end{array}$ & $\begin{array}{l}\text { CgA stain } \\
\text { positivity }\end{array}$ & $\begin{array}{l}\text { Somatostatin } \\
\text { receptor } \\
\text { status }\end{array}$ & SRS \\
\hline 1 & 45 & $\mathrm{~F}$ & $0 / 1$ & Liver & 80 & $S$ & 0 & ND & $\mathrm{N}$ \\
\hline 2 & 50 & $\mathrm{~F}$ & $0 / 1$ & Anus & 100 & $S$ & Strong & 0 & $\mathrm{~N}$ \\
\hline 3 & 53 & $M$ & 2 & Pancreas & 50 & ND & ND & ND & ND \\
\hline 4 & 58 & $\mathrm{~F}$ & $0 / 1$ & Liver & 40 & $S$ & Weak & Weak & ND \\
\hline 5 & 54 & $\mathrm{~F}$ & $0 / 1$ & Pancreas & 30 & $S$ & 0 & ND & $\mathrm{N}$ \\
\hline 6 & 56 & $F$ & $0 / 1$ & Pelvic & $>20$ & $S$ & 0 & 0 & ND \\
\hline 7 & 48 & $M$ & $0 / 1$ & Pancreas & 50 & $\mathrm{~L}$ & Strong & ND & $\mathrm{P}$ \\
\hline 8 & 44 & $M$ & $0 / 1$ & Liver & 50 & $\mathrm{~L}$ & Strong & 0 & $\mathrm{~N}$ \\
\hline 9 & 55 & $\mathrm{~F}$ & $0 / 1$ & Liver & $>20$ & $\bar{S}$ & Weak & 0 & ND \\
\hline 10 & 78 & $F$ & 2 & Anus & $>20$ & $S$ & Strong & 0 & ND \\
\hline 11 & 35 & $M$ & 2 & Pancreas & 40 & ND & ND & ND & $\mathrm{N}$ \\
\hline 12 & 72 & $\mathrm{~F}$ & 2 & Pancreas & 25 & $\mathrm{~L}$ & Strong & 0 & $\mathrm{~N}$ \\
\hline 13 & 57 & $\mathrm{~F}$ & $0 / 1$ & Liver & 90 & $S$ & Weak & 0 & ND \\
\hline 14 & 68 & $M$ & 2 & Pancreas & 80 & $S$ & Strong & ND & ND \\
\hline 15 & 29 & $\mathrm{M}$ & $0 / 1$ & Pancreas & $>20$ & $\mathrm{~L}$ & Strong & ND & ND \\
\hline 16 & 37 & $\mathrm{~F}$ & $0 / 1$ & Pancreas & 50 & $\mathrm{~L}$ & Strong & ND & $\mathrm{P}$ \\
\hline 17 & 51 & $\mathrm{~F}$ & $0 / 1$ & Pancreas & 50 & $\mathrm{~L}$ & Strong & 0 & $\mathrm{~N}$ \\
\hline 18 & 47 & $M$ & $0 / 1$ & Pancreas & 80 & $S$ & Strong & ND & ND \\
\hline 19 & 61 & $\mathrm{~F}$ & $0 / 1$ & Liver & 40 & $S$ & Weak & 0 & $\mathrm{~N}$ \\
\hline
\end{tabular}

CgA, chromogranin A; SRS, somatostatin receptor scintigraphy; ND, not done; L, large; S, small; P, positive; N, negative. 


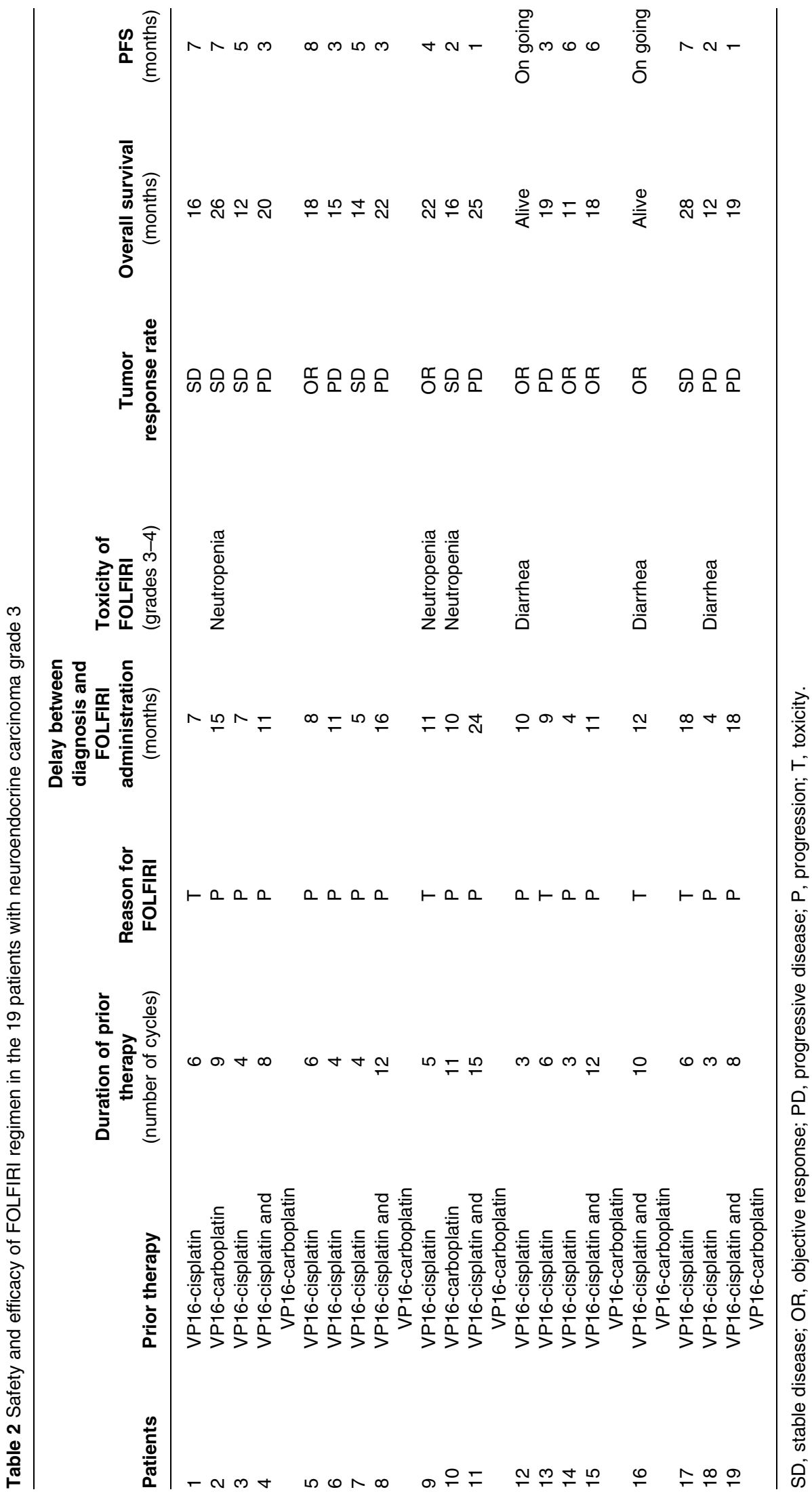




\section{Safety evaluation}

Six patients (32\%) had a grades 3-4 toxicity requiring dose reductions. Among them, four patients experienced at least one episode of grade 3 toxicity (neutropenia, $n=1$; diarrhea, $n=3$ ) and two developed grade 4 neutropenia without fever. Chemotherapy was stopped in one of them due to the occurrence of repeated grades 3-4 neutropenia despite the administration of granulocyte colony stimulating factor (G-CSF). No death occured due to toxicity (Table 2).

\section{Tumor response rate}

Among the 19 patients treated with the FOLFIRI regimen, $6(31 \%)$ had objective response (OR), $6(31 \%)$ stable disease (SD), and $7(38 \%)$ disease progression. Disease control $(\mathrm{OR}+\mathrm{SD})$ was achieved in eight of the 14 patients $(57 \%)$ who received FOLFIRI after progression with etoposide-platinum combination (Table 2).

\section{Survival}

Median overall survival of the whole population $(n=39)$ was 14 months (1.6-30). In patients being not eligible for second-line treatment with FOLFIRI and receiving $\mathrm{BSC}$, median overall survival was 6.8 months (1.6-30). Median overall survival of patients who received the FOLFIRI regimen $(n=19)$ was 18 months (10.5-28) with a median progression-free survival of 4 months (0.5-7.5; Fig. 1; Table 2).

\section{Discussion}

NECs grade 3 are very rare tumors with an incidence of 2-1 000000 inhabitants per year (Ahlman et al. 2008, Yao et al. 2008). They represent only $5-10 \%$ of neuroendocrine neoplasms (Nilsson et al. 2006, Bettini et al. 2008). This series is the first one that suggests a potential efficacy of FOLFIRI regimen as second-line chemotherapy in patients with digestive NECs grade 3 . In this monocentric retrospective study, an OR rate was

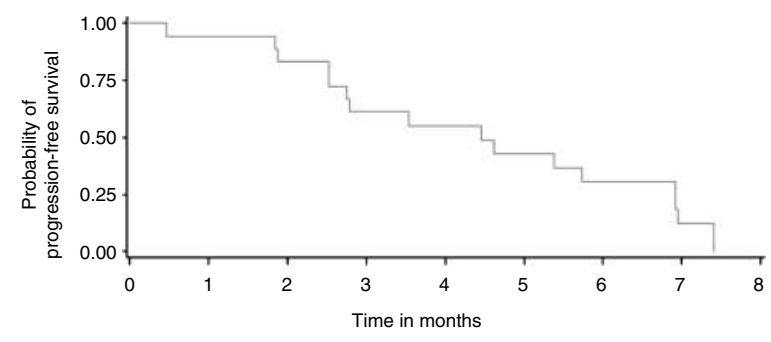

Figure 1 Progression-free survival in patients with neuroendocrine carcinoma grade 3 treated with FOLFIRI regimen. obtained in $31 \%$ of patients, and the rate of disease control was $62 \%$. The median progression-free survival and the overall survival were 4 and 18 months respectively. A relatively high proportion of patients $(32 \%, n=6)$ were considered to have a liver primary as previously described by Hainsworth et al. (2006) This may be due to the necessity to begin chemotherapy promptly without an exhaustive search of the primary tumor.

First-line chemotherapy with etoposide-cisplatin is the standard regimen for NECs grade 3, however, data about potentially efficient second-line treatments are lacking (Nilsson et al. 2006, Ahlman et al. 2008, Strosberg et al. 2010). Efficacy of irinotecan was demonstrated in colorectal cancer with two doselimiting toxicities, late diarrhea and febrile neutropenia (Cunningham et al. 1998, Rougier et al. 1998). This drug has two main metabolic pathways that predominantly take place in the liver; administration to patients with liver dysfunction remains a problem and total bilirubin level has been shown to predict the probability of severe neutropenia (Mathijssen et al. 2001, Raymond et al. 2002). Conversely, irinotecan- or topotecan-based regimens have demonstrated efficacy in lung cancer, especially in small cell lung cancer which share some similarities with PEDCs. Noticeably in a large randomized trial in 154 patients with extensive small cell lung cancer, irinotecan and cisplatin provided higher overall survival rate compared with etoposide and cisplatin (Langer 2001a, Noda et al. 2002). Moreover, intravenous topotecan is currently the second-line agent of choice in patients with small cell lung cancer (O'Brien et al. 2007). In a French series of 20 patients with malignant pancreatic well-differentiated NETs treated in firstline, FOLFIRI regimen did not show major antitumoral activity as first-line therapy with a tumor control rate of $75 \%$ at 6 months and only one OR (Brixi-Benmansour et al. 2011). In our study, 20 of the 39 patients were not eligible for FOLFIRI regimen as second-line therapy due to poor general condition or severe cholestasis due to major liver involvement. These two contraindications are not rare in patients with digestive NECs grade 3 due to the aggressiveness of the disease. Likewise, this accounts for the necessity of dose reduction at first irinotecan infusion in five of the 19 patients.

Median overall survival of our whole population (14 months) is in accordance with previous reports about efficacy of etoposide-platinum combination (Moertel et al. 1991, Mitry et al. 1999). In our series, overall survival in non eligible patients for FOLFIRI was short (6.8 months) due to the disease severity that precluded administration of a second-line therapy. 
In contrast, the overall survival of patients treated with FOLFIRI was definitely encouraging (18 months). However, a discrepancy between this result and the short progression-free survival (4 months) could appear somewhat surprising. One hypothesis is that after FOLFIRI withdrawal in case of progression, many patients remain in acceptable condition and can benefit from a subsequent antitumoral treatment. Otherwise, these patients likely have a favorable natural history and a slow tumor growth.

Six of the 19 patients who were able to receive the FOLFIRI regimen experienced OR (rate: $31 \%$ ) and six had SD (rate: $31 \%$ ). The disease control rate $(62 \%)$ appeared to be promising knowing that patients with this tumor type usually experience prompt general status deterioration after failure of first-line chemotherapy. In addition, seven patients achieved an OR or SD (disease control rate of 57\%) while they had tumor progression under etoposide-platinum combination.

Recently, promising results using temozolomidebased chemotherapy (alone or in combination with capecitabine \pm bevacizumab) as second-line in 25 patients with NECs grade 3 were reported (Welin et al. 2011). The response rate was quite similar to that of observed in our study with one complete response and seven partial responses (overall response rate of $33 \%$ ) and a median progression-free survival of 6 months. Median survival from initial diagnosis was 22 months (22-42). It is possible that this better result was due to a selection of patients in good condition. Furthermore, 14 of these 25 patients had positive SRS and 12 had an NEC grade 3 with a Ki-67 index between 21 and $30 \%$. These two features are usually associated with a better prognosis (Welin et al. 2011). In our series, among the 19 patients treated in second-line therapy, 13 patients had a Ki-67 index $>30 \%(68 \%)$, five (26\%) had an ECOG performance status of 2, and only two SRS were positive among the 10 performed.

Main side effects were neutropenia and diarrhea (grades 3-4, 32\%) similar to the patients with colorectal cancer receiving FOLFIRI (Cunningham et al. 1998, Rougier et al. 1998). Though there was no toxic death in our series, a careful management of these toxicities is required with dose adaptation and/or easy use of G-CSF. Only one patient discontinued this regimen due to recurrent grades 3-4 neutropenia.

Our study is the first report on the antitumoral activity and the feasibility of the FOLFIRI regimen administration as second-line chemotherapy in patients with NECs grade 3 and acceptable general condition without severe cholestasis. Since the presentation of these results, the French guidelines have integrated this regimen as being an option after etoposide-platinum combination failure (http://www.snfge.asso.fr). The FOLFIRI regimen should be now tested in a prospective multicenter trial.

\section{Declaration of interest}

The authors declare that there is no conflict of interest that could be perceived as prejudicing the impartiality of the research reported.

\section{Funding}

This research did not receive any specific grant from any funding agency in the public, commercial or not-for-profit sector.

\section{References}

Ahlman H, Nilsson O, McNicol AM, Ruszniewski P, Niederle B, Ricke J, Jensen R, Kos-Kudla B, Oberg K, O'Connor JM et al. 2008 Poorly-differentiated endocrine carcinomas of midgut and hindgut origin.

Neuroendocrinology 87 40-46. (doi:10.1159/000109976)

Bettini R, Boninsegna L, Mantovani W, Capelli P, Bassi C, Pederzoli P, Delle Fave GF, Panzuto F, Scarpa A \& Falconi M 2008 Prognostic factors at diagnosis and value of WHO classification in a mono-institutional series of 180 non-functioning pancreatic endocrine tumours. Annals of Oncology 19 903-908. (doi:10.1093/annonc/ mdm552)

Brixi-Benmansour H, Jouve JL, Mitry E, Bonnetain F, Landi B, Hentic O, Bedenne L \& Cadiot G 2011 Phase II study of first-line FOLFIRI for progressive metastatic welldifferentiated pancreatic endocrine carcinoma. Digestive and Liver Disease 43 912-916. (doi:10.1016/j. dld.2011.07.001)

Cunningham D, Pyrhonen S, James RD, Punt CJ, Hickish TF, Heikkila R, Johannesen TB, Starkhammar H, Topham CA, Awad L et al. 1998 Randomised trial of irinotecan plus supportive care versus supportive care alone after fluorouracil failure for patients with metastatic colorectal cancer. Lancet 352 1413-1418. (doi:10.1016/S01406736(98)02309-5)

Ducreux MP, Boige V, Leboulleux S, Malka D, Kergoat P, Dromain C, Elias D, de Baere T, Sabourin JC, Duvillard P et al. 2006 A phase II study of irinotecan with 5-fluorouracil and leucovorin in patients with pretreated gastroenteropancreatic well-differentiated endocrine carcinomas. Oncology 70 134-140. (doi:10.1159/ 000093004)

Fjallskog ML, Granberg DP, Welin SL, Eriksson C, Oberg KE, Janson ET \& Eriksson BK 2001 Treatment with cisplatin and etoposide in patients with neuroendocrine tumors. Cancer 92 1101-1107. (doi:10.1002/10970142(20010901)92:5<1101::AID-CNCR1426>3.0. $\mathrm{CO} ; 2-\mathrm{V})$

Hainsworth JD, Spigel DR, Litchy S \& Greco FA 2006 Phase II trial of paclitaxel, carboplatin, and etoposide in advanced poorly differentiated neuroendocrine 
carcinoma: a Minnie Pearl Cancer Research Network Study. Journal of Clinical Oncology 24 3548-3554. (doi:10.1200/JCO.2005.05.0575)

Hentic O, Couvelard A, Rebours V, Zappa M, Dokmak S, Hammel P, Maire F, O'Toole D, Levy P, Sauvanet A et al. $2011 \mathrm{Ki}-67$ index, tumor differentiation, and extent of liver involvement are independent prognostic factors in patients with liver metastases of digestive endocrine carcinomas. Endocrine-Related Cancer 18 51-59. (doi:10.1677/ERC-09-0319)

Langer CJ 2001 $a$ The emerging world role of irinotecan in lung cancer. Oncology 15 15-21.

Langer CJ 2001b Treatment of non-small-cell lung cancer in North America: the emerging role of irinotecan. Oncology 15 19-24.

Madeira I, Terris B, Voss M, Denys A, Sauvanet A, Flejou JF, Vilgrain V, Belghiti J, Bernades P \& Ruszniewski P 1998 Prognostic factors in patients with endocrine tumours of the duodenopancreatic area. Gut 43 422-427. (doi:10.1136/gut.43.3.422)

Mathijssen RH, van Alphen RJ, Verweij J, Loos WJ, Nooter K, Stoter G \& Sparreboom A 2001 Clinical pharmacokinetics and metabolism of irinotecan (CPT-11). Clinical Cancer Research 7 2182-2194.

Mitry E, Baudin E, Ducreux M, Sabourin JC, Rufie P, Aparicio T, Aparicio T, Lasser P, Elias D, Duvillard P et al. 1999 Treatment of poorly differentiated neuroendocrine tumours with etoposide and cisplatin. British Journal of Cancer 81 1351-1355. (doi:10.1038/ sj.bjc.6690325)

Moertel CG, Kvols LK, O’Connell MJ \& Rubin J 1991 Treatment of neuroendocrine carcinomas with combined etoposide and cisplatin. Evidence of major therapeutic activity in the anaplastic variants of these neoplasms. Cancer 68 227-232. (doi:10.1002/1097-0142(19910715)68:2< 227::AID-CNCR2820680202>3.0.CO;2-I)

Nilsson O, Van Cutsem E, Delle Fave G, Yao JC, Pavel ME, McNicol AM, Sevilla Garcia MI, Knapp WH,

Kelestimur F, Sauvanet A et al. 2006 Poorly differentiated carcinomas of the foregut (gastric, duodenal and pancreatic). Neuroendocrinology 84 212-215. (doi:10.1159/000098013)

Noda K, Nishiwaki Y, Kawahara M, Negoro S, Sugiura T, Yokoyama A, Fukuoka M, Mori K, Watanabe K, Tamura T et al. 2002 Irinotecan plus cisplatin compared with etoposide plus cisplatin for extensive small-cell lung cancer. New England Journal of Medicine 346 85-91. (doi:10.1056/NEJMoa003034)

O'Brien M, Eckardt J \& Ramlau R 2007 Recent advances with topotecan in the treatment of lung cancer. Oncologist 12 1194-1204. (doi:10.1634/theoncologist.12-10-1194)

Panzuto F, Nasoni S, Falconi M, Corleto VD, Capurso G, Cassetta S, Di Fonzo M, Tornatore V, Milione M, Angeletti S et al. 2005 Prognostic factors and survival in endocrine tumor patients: comparison between gastrointestinal and pancreatic localization. Endocrine-Related Cancer 12 1083-1092. (doi:10.1677/erc.1.01017)
Raymond E, Boige V, Faivre S, Sanderink GJ, Rixe O, Vernillet L, Jacques C, Gatineau M, Ducreux M \& Armand JP 2002 Dosage adjustment and pharmacokinetic profile of irinotecan in cancer patients with hepatic dysfunction. Journal of Clinical Oncology 20 4303-4312. (doi:10.1200/JCO.2002.03.123)

Rindi G, Klimstra DS, Arnold R, Klöppel G, Bosman FT \& Komminoth P 2010 Nomenclature and classification of neuroendocrine neoplasms of the digestive system WHO classification of tumours of the digestive system. In WHO Classification of Tumours of the Digestive System, 4th edn. WHO: Lyon, France.

Rougier P, Van Cutsem E, Bajetta E, Niederle N, Possinger K, Labianca R, Navarro M, Morant R, Bleiberg H, Wils J et al. 1998 Randomised trial of irinotecan versus fluorouracil by continuous infusion after fluorouracil failure in patients with metastatic colorectal cancer. Lancet 352 1407-1412. (doi:10.1016/S0140-6736(98)03085-2)

Steinmuller T, Kianmanesh R, Falconi M, Scarpa A, Taal B, Kwekkeboom DJ, Lopes JM, Perren A, Nikou G, Yao J et al. 2008 Consensus guidelines for the management of patients with liver metastases from digestive (neuro)endocrine tumors: foregut, midgut, hindgut, and unknown primary. Neuroendocrinology 87 47-62. (doi:10.1159/000111037)

Strosberg JR, Coppola D, Klimstra DS, Phan AT, Kulke MH, Wiseman GA \& Kvols LK 2010 The NANETS consensus guidelines for the diagnosis and management of poorly differentiated (high-grade) extrapulmonary neuroendocrine carcinomas. Pancreas 39 799-800. (doi:10.1097/MPA.0b013e3181ebb56f)

Therasse P, Arbuck SG, Eisenhauer EA, Wanders J, Kaplan RS, Rubinstein L, Verweij J, Van Glabbeke M, van Oosterom AT, Christian MC et al. 2000 New guidelines to evaluate the response to treatment in solid tumors. European Organization for Research and Treatment of Cancer, National Cancer Institute of the United States, National Cancer Institute of Canada. Journal of the National Cancer Institute 92 205-216. (doi:10.1093/jnci/92.3.205)

Welin S, Sorbye H, Sebjornsen S, Knappskog S, Busch C \& Oberg K 2011 Clinical effect of temozolomide-based chemotherapy in poorly differentiated endocrine carcinoma after progression on first-line chemotherapy. Cancer 117 4617-4622. (doi:10.1002/cncr.26124)

Yao JC, Hassan M, Phan A, Dagohoy C, Leary C, Mares JE, Abdalla EK, Fleming JB, Vauthey JN, Rashid A et al. 2008 One hundred years after "carcinoid": epidemiology of and prognostic factors for neuroendocrine tumors in 35,825 cases in the United States. Journal of Clinical Oncology 26 3063-3072. (doi:10.1200/JCO.2007.15.4377)

Received in final form 28 August 2012

Accepted 31 August 2012

Made available online as an Accepted Preprint 31 August 2012 